\title{
Histological, surface ultrastructural, and histochemical study of the stomach of red piranha, Pygocentrus nattereri (Kner)
}

\author{
Saroj Kumar Ghosh, Padmanabha Chakrabarti
}

Received - 17 June 2015/Accepted - 07 December 2015. Published online: 31 December 2015; (Inland Fisheries Institute in Olsztyn, Poland Citation: Ghosh S.K., Chakrabarti P. 2015 - Histological, surface ultrastructural, and histochemical study of the stomach of red piranha, Pygocentrus nattereri (Kner) - Arch. Pol. Fish. 23: 205-215.

\begin{abstract}
The structural characterization and function of the stomach in the omnivore Pygocentrus nattereri were described using light and scanning electron microscopy. The sac-like stomach was morphologically divided into the cardiac and pyloric regions. The histological structure of the stomach consisted of four layers of the mucosa, submucosa, muscularis, and serosa. The superficial epithelium of the cardiac stomach was lined with columnar epithelial cells and the glandular epithelium contained numerous gastric glands. Gastric glands were completely absent in the pyloric portion. The mucosal surface of the stomach was a meshwork of various folds, provided with oval or rounded columnar epithelial cells which were densely packed with short, stubby microvilli. The occasional presence of conspicuous gastric pits was surrounded by epithelial cells. The localization and chemical nature of acid and neutral mucins in the various cells of the stomach was studied by employing combined the Alcian Blue-Periodic Acid Schiff (AB-PAS) technique. The deposition of glycogen was detected in the gastric glands as well as in the epithelial lining of the stomach. The utmost reactions for protein and tryptophan were recorded in the gastric glands of mucosa. The cellular organization and histochemical characterization of the stomach are discussed in relation to the feeding and digestion of the fish concerned.
\end{abstract}

Keywords: cellular architecture, scanning electron microscopy, histochemistry, stomach, Pygocentrus nattereri

\footnotetext{
S.K. Ghosh [ڤ]

Department of Zoology, Bejoy Narayan Mahavidyalaya, Itachuna, Hooghly-712 147, West Bengal, India

e-mail: saroj.fisherylab@gmail.com

P. Chakrabarti

Fisheries Laboratory, Department of Zoology, The University of Burdwan, Golapbag, Burdwan-713 104, West Bengal, India
}

\section{Introduction}

Fish show extensive diversity of food and feeding habits. Depending on the type of food consumed, some modifications take place in the digestive tract, especially in the stomach. Some fish have stomachs (Diaz et al. 2003, Carrason et al. 2006), while others do not (Klumpp and Nichols 1983, Unal et al. 2001), or the stomach is modified as an intestinal bulb or swelling (Dasgupta 2001, Naguib et al. 2011). The cellular organization and shape of the stomach in teleosts are variable and reflect functional morphological differentiation for adaptation (Reifel and Travill 1978). In teleosts, the stomach is simpler than that of higher vertebrates, but it contain gastric glands that secrete both pepsinogen and hydrochloric acid (Rebolledo and Vial 1979). The morpho-histological peculiarities of the stomach among teleosts have been investigated by many researchers (Osman and Caceci 1991, Chang and Lin 1992, Murray et al. 1994, Ba-Omar et al. 1998, Arellano et al. 2001, El-Bakary 2007, Musa et al. 2013, Ghosh and Chakrabarti 2015); however, very little information is available on the microscopic anatomy of stomach mucosa (Gargiulo et al. 1997, Naguib et al. 2011, Chakrabarti and Ghosh 2014). Moreover, lacunae still remain regarding the localization and significance of the chemical constitution occurring in the cells lining the stomach and their role in digestion.

\footnotetext{
C Copyright by Stanisław Sakowicz Inland Fisheries Institute in Olsztyn.

(c) 2015 Author(s). This is an open access article licensed under the Creative Commons Attribution-NonCommercial-NoDerivs License (http://creativecommons.org/licenses/by-nc-nd/3.0/).
} 
The aim of the present work was to describe the structural characteristics and histochemical features of the stomach in the predatory freshwater teleost Pygocentrus nattereri (Characiformes, Serrasalmidae), which is an excellent commercial fish species for aquaculture. It is a dangerous omnivore and is primarily a scavenger and forager, the natural diet of which includes not only live fishes but also worms, snails, insects, crustaceans, nuts, and seeds (Fink 1993).

\section{Materials and methods}

\section{Tissue collection}

Adult specimens of P. nattereri (ranged $29.40 \pm 2.81$ $\mathrm{cm}$ in total length; $\mathrm{n}=12$ ) were obtained from the local freshwater body of Burdwan $\left(23.2333^{\circ} \mathrm{N}\right.$, $87.8667^{\circ} \mathrm{E}$ ), West Bengal, India. The fish were anesthetized and euthanized with an overdose of tricaine methone-sulphonate (MS 222) and then anatomized with a longitudinal incision along the ventral side. The stomach portion was dissected, cut into small pieces, and immediately processed for the respective studies.

\section{Histological preparation}

Tissue fragments of stomach were fixed in aqueous Bouin's solution for 16-18 h. After fixation, the tissues were washed with $70 \%$ ethanol, dehydrated in graded series of ethanol, and cleared in xylene. Then the tissues were infiltrated in paraffin wax at $56-58^{\circ} \mathrm{C}$ under a thermostat vacuum paraffin-embedding bath for a period of $1 \mathrm{~h}$. Serial paraffin sections were cut at a $4 \mu \mathrm{m}$ thickness using a rotary microtome (Weswox). After routine histological processing, deparaffinized sections were stained with Delafield's Hematoxylin-Eosin (HE) and Mallory's Triple (MT) stain (Mallory 1936). The stained slides were mounted with DPX, and examined and photographed under a LEICA EC3 microscope.

\section{Scanning electron microscopical (SEM) preparation}

The stomach was incised longitudinally to expose the mucosal surface, spread out, and pinned with the mucosal surface upper side on cork sheets. The excess mucus of the mucosal surface was removed by repeated rinsing with $1 \%$ Tween 40 solution. After rinsing with $0.1 \mathrm{M}$ cacodylate buffer ( $\mathrm{pH}$ 7.3), the samples were fixed in $2.5 \%$ glutaraldehyde for $24 \mathrm{~h}$ at $4^{\circ} \mathrm{C}$ and post fixed with $1 \%$ osmium tetroxide in $0.1 \mathrm{M}$ cacodylate buffer (pH 7.4) for $2 \mathrm{~h}$. The fixed tissues were washed thoroughly in the same buffer and dehydrated in ascending series of acetone followed by isoamyl acetate. The tissues were dried in a critical point drier (Hitachi 8CP2), mounted on metal stubs, coated with gold palladium (20 nm thick), and examined under a Hitachi S-530 scanning electron microscope.

\section{Histochemical preparation}

Small pieces of stomach were fixed in 10\% neutral formalin for $16 \mathrm{~h}$. The tissues were passed through graded series of ethanol, cleared in xylene, and embedded in paraffin wax at $52-54^{\circ} \mathrm{C}$ in a vacuum embedding bath. Sections were cut to an $8 \mu \mathrm{m}$ thickness and subjected to various histochemical reactions: the combined Alcian Blue-Periodic Acid Schiff (AB-PAS) technique for acid and neutral mucins (Mowry 1956), Best's Carmine (BC) reaction for glycogen (Best 1906), Mercury-Bromophenol Blue (MBB) method for proteins (Mazia et al. 1953), and Dimethylaminobenzaldehyde (DMAB)-nitrite method for tryptophan (Adams 1957). The stained slides were analyzed and photographed with a LEICA EC3 microscope.

\section{Results}

\section{Histology}

The stomach of $P$. nattereri is generally a sac-like structure that is distinguished by the cardiac and pyloric regions. Histologically, the stomach wall is comprised of four layers of the mucosa, submucosa, muscularis, and 

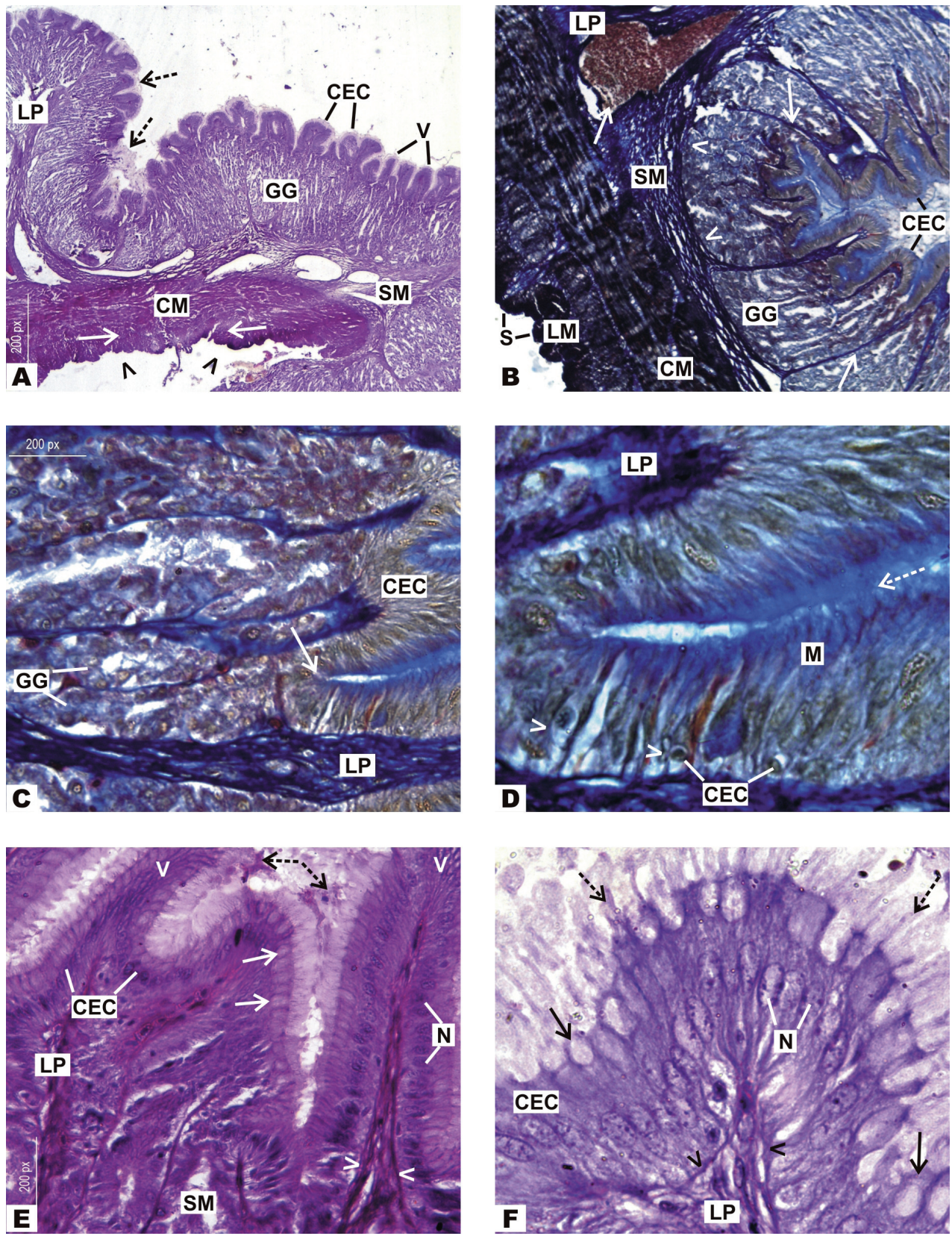

Figure 1. Photomicrographs of histological sections of the stomach of P. nattereri stained with Delafield's Hematoxylin-Eosin (HE) and Mallory's triple (MT) stain. (A) Wall of the cardiac stomach comprised of mucosa with numerous villi-like structures (V), submucosa (SM) forming lamina propria (LP), muscularis with inner circular muscle layer (CM) and outer longitudinal muscle layer (LM) (solid arrows) and serosa (arrow heads). Note the presence of columnar epithelial cells (CEC) and gastric glands (GG) in mucosa and mucin film (broken arrows) over the free border of CEC (HE) at the 40× magnification. (B) Mucosa with a single layer of CEC and GG distinguished from SM by distinct basement membrane (BM) (arrow heads). Note the presence of lamina propria (LP) with blood vessels (broken arrow), inner CM, outer LM and peripheral serosa (S) (MT) at the $100 \times$ magnification. (C) Showing surface epithelium with tightly packed CEC and glandular epithelium with numerous GG supported by LP. Solid arrow indicates the crypt region (MT) at the $400 \times$ magnification. (D) Higher magnification of mucosa exhibits the single layer of CEC with basally placed conspicuous nuclei (N) (arrow heads). Note the presence of LP and mucin film (broken arrow) over CEC (MT) at the $1000 \times$ magnification. (E) Mucosa of pyloric stomach is thrown into finger-like villi (V) covered by top plate (broken arrows), lined with a single layer of CEC with prominent $\mathrm{N}$ and mucous cells (solid arrows). Mucosa is separated from SM by BM (arrow heads). LP indicates lamina propria (HE) at the $400 \times$ magnification. (F) Higher magnification of mucosa of pyloric stomach shows CEC with distinct $\mathrm{N}$ bounded by a thin BM (arrow heads) which separates from LP. Note the presence of MC (solid arrows) in between CEC and the mucus thread (broken arrows) at the free border of the epithelial cells (HE) at the $1000 \times$ magnification. 
serosa (Figs. 1A and B). The mucosa is thrown into thick longitudinal folds forming short villi- like manifestations which are studded with minute depressions or gastric pits (Figs. 1B and C). Each fold subsequently gives rise to tiny secondary folds. The mucosa of the cardiac stomach is made up of two types of epithelium: the outer superficial epithelium and the inner glandular epithelium. The superficial epithelium contains a single layer of simple columnar epithelial cells with basally located conspicuous oval nuclei (Fig. 1D). These cells are cylindrical in shape and almost uniform in size. The free border of epithelial cells is covered by mucus film (Fig. 1A). The glandular epithelium is crowded with numerous gastric glands that occupy the entire mucosa beneath of the superficial epithelium (Figs. 1B and C). The gastric glands usually open into the lumen of the stomach through the gastric pits. The cells of the glands have centrally-located spherical nuclei (Fig. 1C). The gastric glands are closely bounded by a thin strand of connective tissue.

The lumen of the pyloric stomach becomes narrow because of the extensive development of rugae. The finger-like villi are numerous and covered by a thin top plate (Fig. 1E). The mucosa of the pyloric stomach is lined with columnar epithelial cells with deeply stained nuclei and mucous cells (Figs. 1E and F). Gastric glands are absent in the mucosa.

The submucosa is thin throughout the entire length of the stomach and composed of a network of connective tissue, collagen fibers, and blood capillaries which project into the mucosal folds forming lamina propria. The basement membrane is present in between the mucosa and submucosa (Figs. 1B, E and F). The muscularis layer of the cardiac stomach is less thick than the pyloric stomach. The muscularis is composed of an inner circular and outer longitudinal layer of muscle fibers (Figs. 1A and B). The circular layer is thicker than the longitudinal layer. The serosa is very thin and vascular, and forms the outermost boundary layer of the stomach.

\section{Scanning electron microscopy (SEM)}

Under SEM, the luminal surface of the mucosa is characterized by regular longitudinal folds that are blended with each other to form deep, hidden
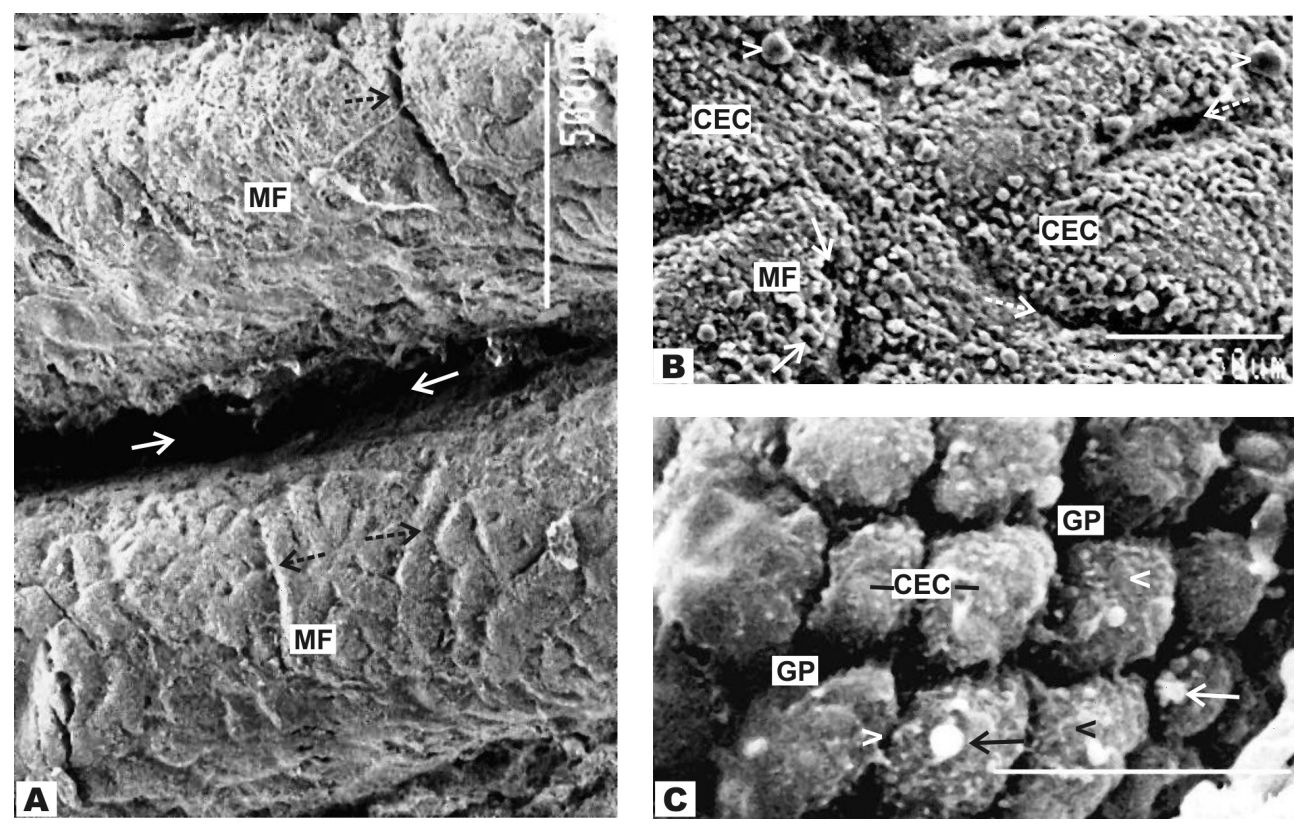

Figure 2. Photomicrographs of the stomach of $P$. nattereri by scanning electron microscopy (SEM). (A) Luminal surface showing deep concavities (solid arrows) in between mucosal folds (MF). Broken arrows mark secondary folds on MF (SEM) at the $80 \times$ magnification. (B) Mucosal surface exhibits gastric pits (GP) (solid arrows) surrounded by cluster of columnar epithelial cells (CEC). Broken arrows indicate discrete furrows on MF. Note mucin mass (arrow heads) over CEC (SEM) at the $600 \times$ magnification. (C) Higher magnification of stomach showing GP encircled by CEC characterized with apical microvilli (arrow heads). Solid arrows indicate the deposition of mucin mass over CEC (SEM) at the $5000 \times$ magnification. 
concavities (Fig. 2A). The longitudinal mucosal folds are embossed with numerous transverse secondary folds. The mucosa of the stomach is typified by compactly organized oval or round shaped columnar epithelial cells (Figs. 2B and C). The epithelial cell surface is provided with short, stubby, apical microvilli (Fig. 2C). The occasional presence of mucin mass adhered to the epithelial surface, and few gastric pits encircled by the group of epithelial cells are observed in this region (Figs. 2B and C).

\section{Histochemistry}

\section{Detection of mucopolysaccharides (AB-PAS)}

The combined AB-PAS reaction furnishes a bluish-purple color of varying intensity according to the acid and neutral mucin content of the different layers in the stomach. This combined test shows a glossy blue color because of $\mathrm{AB}$ for acid mucin and bright purple color for the PAS reaction because of the presence of neutral mucin exclusively. In $P$. nattereri, the columnar epithelial cells of the superficial epithelium and secreted luminal mucin took only the deep purple color, which confirms the presence of a profuse quantity of neutral mucin (Figs. 3A and B). Conversely, the gastric glands of the glandular epithelium impart a purple-bluish color with this test suggesting the presence of both neutral and acidic mucopolysaccharides (Figs. 3B, C and D). The basement membrane (Fig. 3D) and submucosal connective tissue traversed by blood vessels (Fig. 3B) positively reacted with this stain, but the muscularis layer exhibited a mild reaction (Figs. 3A and B). The moderate AB-PAS reaction was found to be associated in the serosa penetrated by blood vessels (Fig. 3A).

\section{Detection of glycogen (Best's Carmine)}

Best's Carmine reaction shows intense red color in the columnar epithelial cell lining as well as in the gastric glands of the mucosa in P. nattereri (Figs. 4A and $\mathrm{B})$. This indicates that a considerable amount of glycogen is present in these cells. The connective tissues of the lamina propria showed a weak reaction; however, the blood vessels in the submucosa reacted positively to the glycogen histochemical test. The moderate reaction of glycogen was noted in the muscularis layer and the serosa (Fig. 4A).

\section{Detection of protein (Mercury Bromophenol blue)}

This histochemical test was employed to locate protein material associated with various layers of the stomach. The presence of protein material with varying intensities imparts a deep blue color in the mucosa, muscularis layer, and the serosa (Fig. 5A). Connective tissue fibers of submucosa forming lamina propria exhibited a weak reaction, but the blood vessels in the submucosa were also intensely stained with protein (Figs. 5A and B). Maximum protein reaction was encountered in the columnar epithelial cells and gastric glands of the mucosa.

\section{Detection of tryptophan \\ (Dimethylaminobenzaldehyde-nitrite)}

In $P$. nattereri, the columnar epithelial cells of the mucosal lining exhibited a moderate to feeble tryptophan reaction (Fig. 6A). However, the gastric glands seem to be intense blue granular structures with this test indicating the presence of tryptophan containing zymogen granules (Figs. 6A and B). The submucosa, muscularis layer, and serosa were negative for this histochemical reaction.

\section{Discussion}

The stomach is part of the alimentary canal, and is adapted for the storage and digestion of food (Mehrotra and Khanna 1969). In P. nattereri, the stomach is voluminous and sac-like because the voracious, scavenger feeding habits of this fish means it accumulates a wide variety of food in its diet. The size and volume of the stomach in fish depends on feeding behavior and particularly on the nature of the food and the size of the prey (Nikolsky 1963). The 

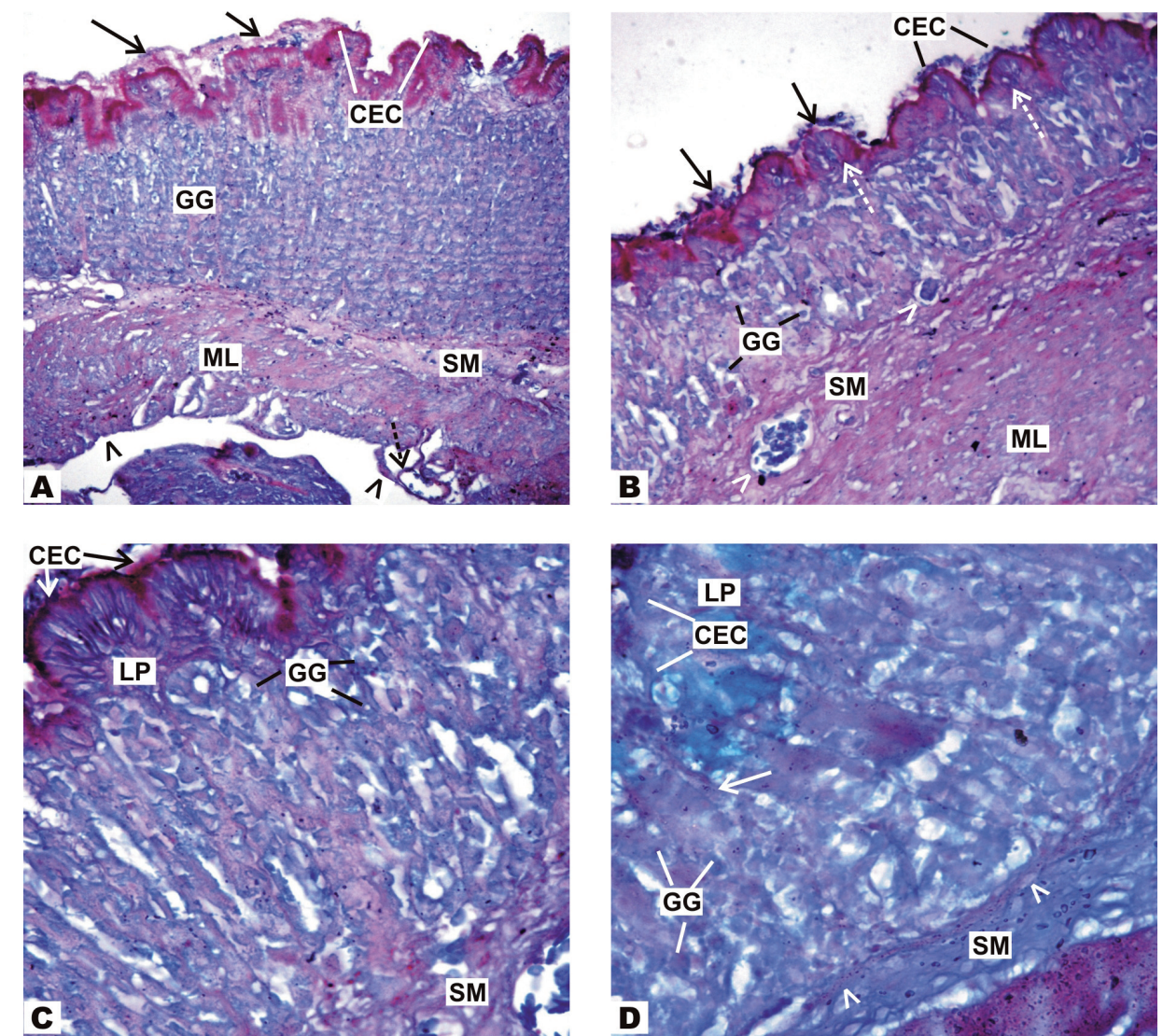

Figure 3. Photomicrographs of the section of stomach of $P$. nattereri showing combined Alcian Blue-Periodic Acid Schiff (AB-PAS) reaction for acid and neutral mucins. (A) Localization of neutral mucin in the columnar epithelial cells (CEC) along with secreted luminal mucin (solid arrows). Note moderate AB-PAS reaction in gastric glands (GG) of mucosa, submucosa (SM), muscularis layer (ML), and blood vessel (BV) (broken arrow) of serosa (arrow heads) (AB-PAS) at the $100 \times$ magnification. (B) Showing deep PAS reaction in CEC including secreted luminal mucus film (solid arrows) and moderate AB-PAS reaction in GG, lamina propria (LP), and SM with BV (arrow heads). ML marks muscularis layer (AB-PAS) at the $150 \times$ magnification. (C) Showing intense PAS reaction in the border (solid arrows) of CEC and moderate AB-PAS reaction in LP and GG. SM indicates submucosa (AB-PAS) at the $400 \times$ magnification. (D) Displaying grievous PAS reaction in CEC and moderate AB-PAS reaction in GG and LP. Note positive reaction in basement membrane (arrow heads) and SM. Solid arrow marks the crypt region (AB-PAS) at the $600 \times$ magnification.

stomach is usually large in fish that swallow large prey or consume large amounts of food at a time.

The general histology of the stomach in $P$. nattereri with four layers of mucosa, submucosa, muscularis, and serosa is similar to that of other teleosts (Ba-Omar et al. 1998, Arellano et al. 2001, Chakrabarti and Ghosh 2014). However, there are some disparities in the cellular characterization of different regions. In the present investigation, the division of the regions in the stomach into cardiac or pyloric is based upon the presence of gastric glands. Gastric glands are present in the anterior cardiac portion of the stomach, whereas they are absent in the posterior pyloric region. This was also reported by
Cao and Wang (2009), Naguib et al. (2011), and Ghosh and Chakrabarti (2015). In P. nattereri, the well-developed cardiac region embossed with gastric glands is the principal site for gastric digestion. The gastric glands are oxynticopeptic cells that produce both pepsinogen and hydrochloric acid. Similar findings are also described in other fishes by Smith (1989), Diaz et al. (2003), and Xiong et al. (2011).

The conspicuous columnar epithelial cells lining the gastric mucosa of the stomach discharge their secretion, mucin, by exocytosis. The gastric mucosa with its simple columnar epithelium is for the absorption of easily digestible molecules with the aid of neutral mucin (Grau et al. 1992). The mucus in the 

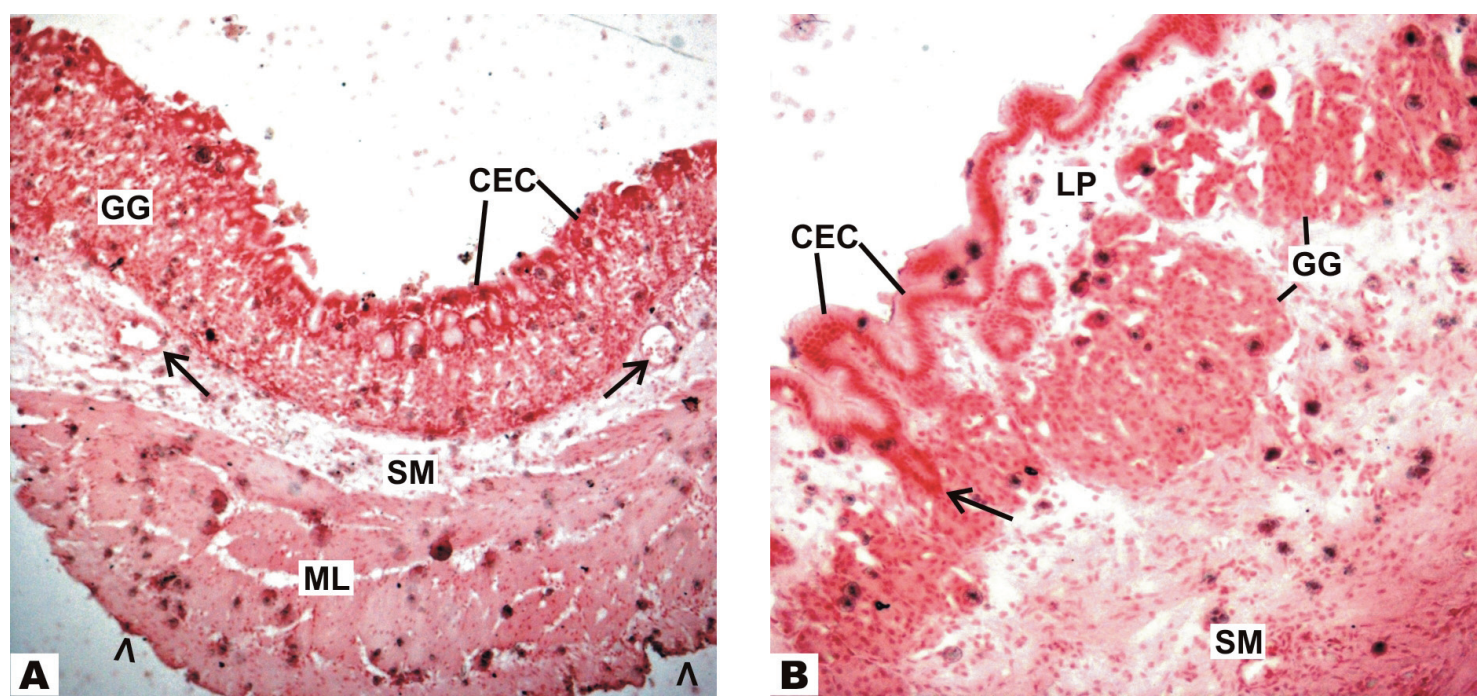

Figure 4. Photomicrographs of the section of stomach of P. nattereri showing Best's Carmine (BC) reaction for glycogen. (A) Intense localization of glycogen in columnar epithelial cells (CEC) and gastric glands (GG) of mucosa. Submucosa (SM) displays weak reaction and muscularis layer (ML) shows moderate reaction. Note positive reaction in blood vessels (BV) of SM and acute reaction in serosa (arrow heads) (BC) at the $100 \times$ magnification. (B) CEC and GG of mucosa contain concentrated deposition of glycogen. Note the weak reaction in lamina propria (LP) and SM. Arrow marks the crypt region (BC) at the $400 \times$ magnification.
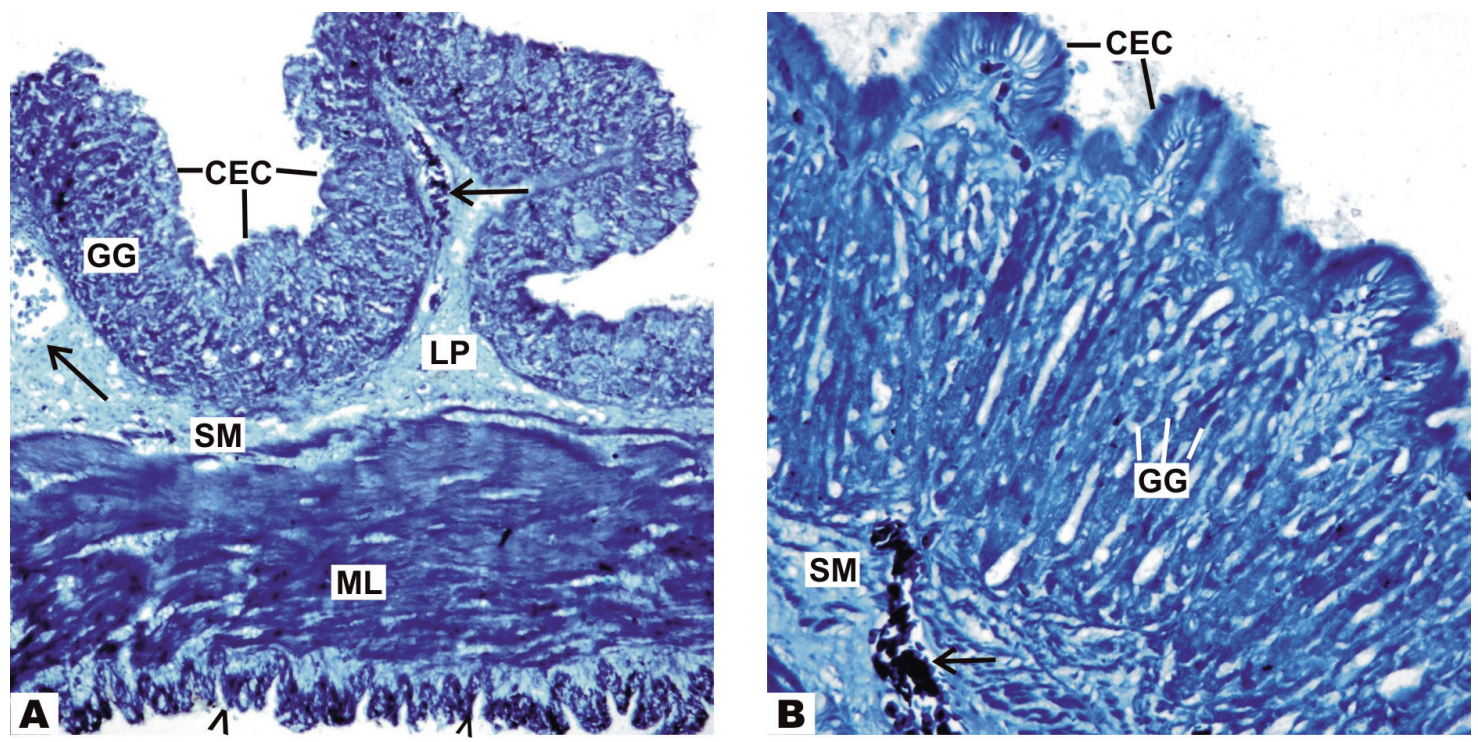

Figure 5. Photomicrographs of the section of stomach of $P$. nattereri show the Mercury Bromophenol Blue (MBB) reaction for protein. (A) Deep reaction in columnar epithelial cells (CEC) and gastric glands (GG) of mucosa, blood vessels (BV) of submucosa (SM), muscularis layer (ML), and serosa (arrow heads). Lamina propria (LP) shows weak reaction (MBB) at the $100 \times$ magnification. (B) Maximum localization of protein in CEC and GG of mucosa. SM shows feeble reaction, but BV displays intense protein reaction (MBB) at the $400 \times$ magnification.

stomach is believed to help in the conduction of food and to provide efficient protection under different gastric conditions (Murray et al. 1994). Ba-Omar et al. (1998) opined that the mucous cells in the stomach with a digestive function could be an appropriate adaptation against the hypersecretion of acid that might damage stomach mucosa. The enhanced populations of goblet cells probably indicate the need for increased mucosa protection and lubrication for fecal expulsion (Murray et al. 1994).

The muscular layer of the stomach in $P$. nattereri is similar to that of other fishes, and is composed of 

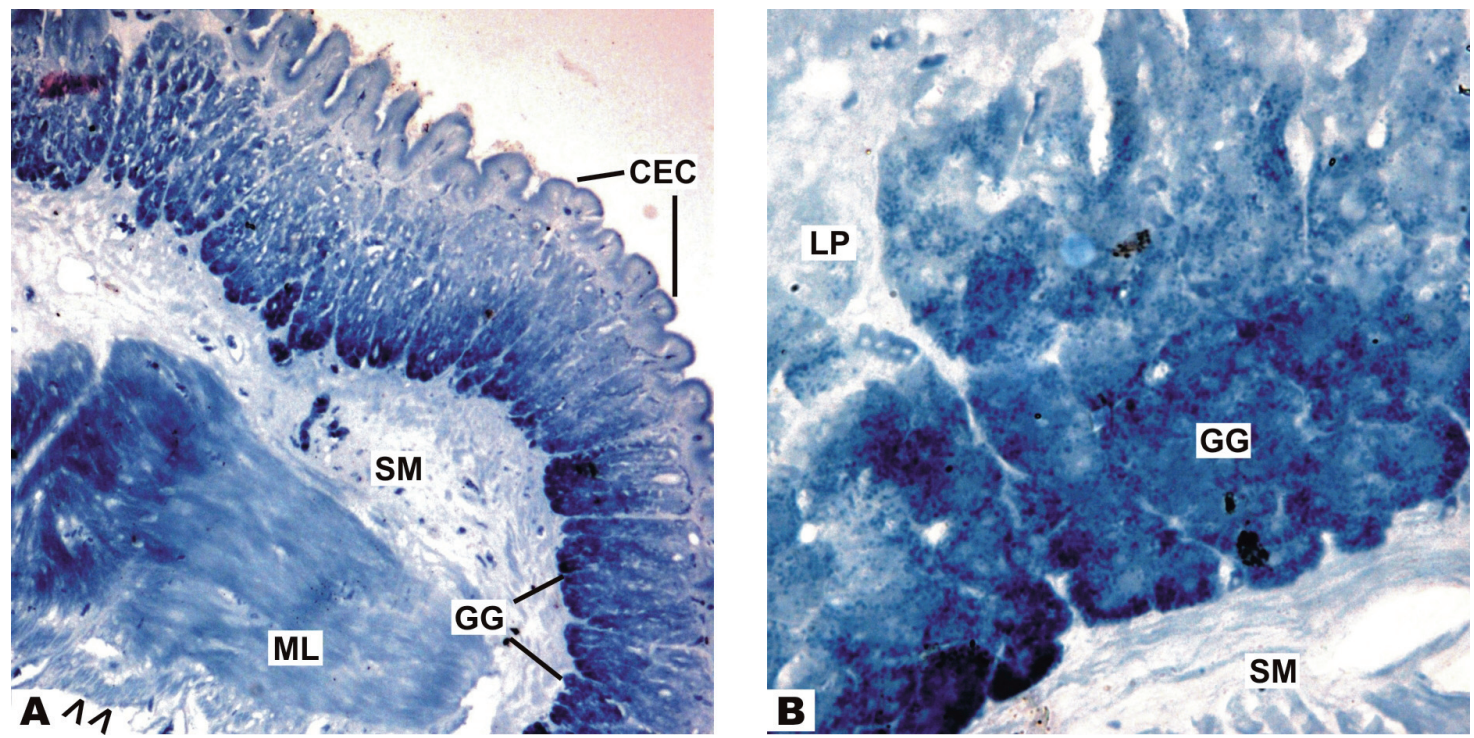

Figure 6. Photomicrographs of the section of stomach of $P$. nattereri show Dimethylaminobenzaldehyde (DMAB) reaction for tryptophan. (A) Concentrated tryptophan reaction in gastric glands (GG) and moderate reaction in the border of columnar epithelial cells (CEC). Note the weak reaction in submucosa (SM), muscularis layer (ML), and serosa (arrow heads) (DMAB) at the $100 \times$ magnification. (B) Showing maximum localization of tryptophan in GG. Lamina propria (LP) and SM display a negative reaction (DMAB) at the $400 \times$ magnification.

an inner circular layer of smooth muscle and a thinner outer longitudinal layer in close association with the thin serosa (Grau et al. 1992, Murray et al. 1994, Arellano et al. 2001). The well-organized muscular layer in the pyloric region of the stomach has great elasticity and tensile strength (Sriwastwa 1970), and it is characteristic of voracious fish that display considerable digestive activity. Murray et al. (1994) described a thickened inner circular layer of smooth muscle in the pyloric region in association with the formation of the pyloric sphincter.

The complex nature of folding in the stomach mucosa in the fish studied would probably allow for stretching during food consumption and also increase surface area for digestive activity (Sinha and Chakrabarti 1986). Grau et al. (1992) reported a large number of primary longitudinal folds which contained secondary folds in the stomach of Seriola dumerili (Risso). The presence of gastric pits, the secretion of which drains into the lumen of the stomach, is related to digestion time and voracious feeding (Moshin 1962). The mucosal surface of the stomach is typified by oval or rounded columnar epithelial cells with short, stubby microvilli. The mucus film coated with microridges of columnar epithelial cells serves as a protective device against strong acid injury of the stomach wall. According to Osman and Caceci (1991), besides protecting the gastric mucosa, mucins also regulate the $\mathrm{pH}$ of the gastric fluid. This explains the variations in the gastric fluid $\mathrm{pH}$ in different species with different diets.

The histochemical characterization of mucin in experimental fish has been studied extensively in order to establish the chemical nature as well as its importance in digestion. Chemically, mucins are hexoseamine-containing polysaccharides that bind covalently with varying amounts of proteins. Mucins are classified as neutral or acid. Neutral mucins are PAS positive showing a glossy purple color, whereas acid mucins are $\mathrm{AB}$ positive exhibiting a bright blue color. Intermediate colors representing the mixtures of the two forms in the same tissues also occur (Greco et al. 1967). In the present study, the PAS-AB histochemical test shows that the columnar epithelial cells along with the mucosal border are strongly PAS positive, which unequivocally suggests the predominance of neutral mucin. The gastric glands stain a purple-bluish color, and they are probably the source 
of both neutral and acid mucopolysaccharides. Anderson (1986) postulated that mucosubstances might provide the cofactors required for the enzymatic breakdown of food. The mucosubstances are also involved in protecting the gastric mucosa from mechanical destruction by food matter (Petrinec et al. 2005). In the present work, the neutral mucopolysaccharides in the apical portion of the epithelial lining in the stomach have a buffering effect and might serve to protect the underlying layers from chemical and physical damage during trituration (Gisbert et al. 1999). Grau et al. (1992) reported that the presence of neutral mucins related to the absorption of easily digestible substances like disaccharides and short chain fatty acids. Neutral mucosubstances combined with alkaline phosphatase to assist in the digestion and emulsification of food into chyme (Clarke and Witcomb 1980).

The glycogen reaction in the epithelial lining of the stomach could be related to the synthesis and secretion of neutral mucin, which is an active process that requires energy, and the presence of glycogen is the chief source of energy. The higher reaction of Best's Carmine in the gastric glands of $P$. nattereri is related to the synthesis of zymogen granules and ergastic substances in the production of pepsinogen and the secretion of $\mathrm{HCl}$. The localization of feeble glycogen content in the different layers of stomach is also used as a source of energy, but it is not stored there. This concurs with the findings of Anwar and Mahmoud (1975) in the intestine of the Egyptian lizards.

In $P$. nattereri, the protein reaction in the mucosa, muscularis layer, and the serosa of stomach indicates various metabolic and physiological activities. Arellano et al. (2001) identified proteins rich in arginine, lysine, cysteine, and cystine in the surface epithelium, gastric gland, lamina propria-submucosa, and muscular layers of the stomachs of Senegal sole. The gastric glands of $P$. nattereri are strongly positive to bromophenol blue reaction suggesting the presence of enzymatic precursors such as pepsinogen or other digestive enzymes (Grau et al. 1992, Gisbert et al. 1999).

The intense reaction of tryptophan in the gastric glands of $P$. nattereri could be related to their elevated zymogen contents. Conversely, the weak reaction to tryptophan in the columnar epithelial cells along with the mucosa lining of stomach could be related to their negligible amount of zymogen granules. Medeiros et al. (1970) also reported tryptophan, tyrosine, and arginine in the glandular cells of the stomach in Pimelodus maculates. They suggested that the strong tryptophan reaction is probably related to the synthesis and secretion of pepsinogen by the gastric glands of the stomach.

Acknowledgements. The authors are thankful to Dr. Sanjib Ray, Head of the Department of Zoology, University of Burdwan, for providing laboratory facilities and are grateful to Dr. Srikanta Chakraborty, Scientist-in-charge of the University Science Instrument Centre, University of Burdwan, for his technical support during SEM analysis.

Author contributions. P.C. designed and S.K.G. performed the research; S.K.G. wrote and P.C. corrected the manuscript.

\section{References}

Adams C.W.M. 1957 - A p-Dimethylaminobenzaldehyde nitrate method for the histochemical demonstration of tryptophan and related compounds - J. Clin. Pathol. 10: 56-62.

Anderson T.A. 1986 - Histological and cytological structure of the gastrointestinal tract of the luderick, Girella tricuspidata (Pisces, Kyphosidae) in relation to diet - J. Morphol. 190: 109-119.

Anwar I.M., Mahmoud B.I. 1975 - Histological and histochemical studies on the intestine of the Egyptian lizards, Mabuya quinqetaeniata and Chalcides ocellatus Bull. Fac. Sci. 4: 101-108.

Arellano J.M., Storch V., Sarasquete C. 2001 - Histological and histochemical observations in the stomach of the Senegal sole, Solea senegalensis - Histol. Histopathol. 16: 511-521.

Ba-Omar T.A., Victor R., Tobias D.B. 1998 - Histology of the stomach of Aphanius dispar (Rüppell 1828), a cyprinodont fish, with emphasis on changes caused by stress from starvation - Trop. Zool. 11: 11-17.

Best F. 1906 - Uber carmine far bug des glycogens and derkerne - Z. Wiss. Mikr. 3: 319-322.

Cao J.X., Wang W.M. 2009 - Histology and mucin histochemistry of the digestive tract of yellow catfish 
Petteobagrus fulvidraco - Anat. Histol. Embryol. 38: 254-261.

Carrasson M., Grau A., Dopazo L.R., Crespo S. 2006 - A histological, histochemical and ultrastructural study of the digestive tract of Dentex dentex (Pisces, Sparidae) Histol. Histopathol. 21: 579-593.

Chakrabarti P., Ghosh S.K. 2014 - A comparative study of the histology and microanatomy of the stomach in Mystus vittatus (Bloch), Liza parsia (Hamilton) and Oreochromis mossambicus (Peters) - J. Microsc. Ultrastruct. 2: 245-250.

Chang M.H., Lin J.F. 1992 - Gastric histological structure and localization of carbonic anhydrase of tilapia - J. Chin. Soc. Vet. Sc. 18: 243-253.

Clarke A.J., Witcomb D.M. - 1980. A study of the histology and morphology of the digestive tract of the common eel (Anguilla anguilla) - J. Fish Biol.16: 159-170.

Dasgupta M. 2001 - Morphological adaptation of the alimentary canal of four Labeo species in relation to their food and feeding habits - Indian J. Fish. 48: 255-257.

Diaz A.O., Garcia A.M., Devincenti C.V., Goldemberg A.L. 2003 - Morphological and histochemical characterization of the mucosa of the digestive tract in Engrolllis anchoita (Hubbs and Marini, 1935) - Anat. Histol. Embryol. 32: 341-346.

El-Bakary N.E.R. 2007 - Comparative histological study of the digestive tract of Oreochromis aureus and Anguilla anguilla - J. Egypt Ger. Soc. Zool. 53: 29-47.

Fink W.L. 1993 - Revision of the piranha genus Pygocentrus (Teleostei, Characiformes) - Copeia 3: 665-687.

Gallagher M.L., Luczkovich J.J., Stellwag E.J. 2001 - Characterization of the ultrastructure of the gastrointestinal tract mucosa, stomach contents and liver enzyme activity of the pinfish during development - J. Fish Biol. 58: 1704-1713.

Gargiulo A.M., Ceccarelli P., Dall'agelio C., Pedini V. 1997 Ultrastructural study on the stomach of Tilapia spp. (Teleostei) - Anat. Histol. Embryol. 26: 331-336.

Ghosh S.K., Chakrabarti P. 2015 - Histological and histochemical characterization on stomach of Mystus cavasius (Hamilton), Oreochromis niloticus (Linnaeus) and Gudusia chapra (Hamilton): comparative study - J. Basic Appl. Zool. 70: 16-24.

Gisbert E., Sarasquete M.C., Williot P., Castelló-Orvay F. 1999 - Histochemistry of the development of the digestive system of Siberian sturgeon during early ontogeny J. Fish Biol. 55: 596-616.

Grau A., Crespo S., Sarasquete M.C., Gonzalez de Canales M.L. 1992 - The digestive tract of the amberjack Seriola dumerili, Risso: a light and scanning electron microscope study - J. Fish Biol. 41: 287-303.

Greco V., Lauro G., Fabrini A., Torsoli A. 1967 - Histochemistry of the colonic epithelial mucins in normal subjects and patients with ulcerative colitis. A quantitative and histophotometric investigation - Gut, 8: 491-496.

Klumpp D.W., Nichols P.D. 1983 - Nutrition of the Southern Sea garfish Hyporhamphus rnelanoehir: gut passage rate and daily consumption of two food types and assimilation of seagrass components - Mar. Ecol. Prog. Ser. 12: 207-216.

Mallory F.B. 1936 - The aniline blue collagen stain - Stain Technol. 11: 101.

Mazia D., Brewer P.A., Alfert M. 1953 - The cytochemical staining and measurement of protein with mercuric bromophenol blue - Biol. Bull. 104: 57.

Medeiros L.O., Ferris S., Godinha H., Medeiros L.F. 1970 Proteins and polysaccharides of the club shaped cells in the lining epithelium of fish (Pimelodus maculates) digestive tract: histochemical study - Ann. d'Histochimie. 15: 181-186.

Mehrotra B.K., Khanna S.S. 1969 - Histomorphology of the oesophagous and the stomach in some Indian teleost with inference on their adaptational features - Zool. Beitr. Berl. 15: 375-391.

Moshin S.M. 1962 - Comparative morphology and histology of the alimentary canals in certain groups of Indian teleosts - Acta Zool. 43: 79-133.

Mowry R.W. 1956 - Alcian blue technique for the histochemical study of acidic carbohydrates - J. Histochem. Cytochem. 4: 403.

Murray H.M., Wright G.M., Goff G.P. 1994 - A comparative histology and histochemical study of the stomach from three species of pleuronectid, the Atlantic halibut, Hippoglossus hippoglossus, the yellow tail flounder, Pleuronectes ferruginea, and the winter flounder, Pleuronectes americanus - Can. J. Zoology. 72: 1199-1210.

Musa M., Yanuhar U., Susilo E., Soemarno. 2013 - Stomach histological decay of milkfish, Chanos Chanos (Forsskill, 1775): ontogeny, environmental stress, shifting food composition, and disease infection - J. Nat. Sci. Res. 3: 194-200.

Naguib S.A.A., EI-Shabaka H.A., Ashour F. 2011 - Comparative histological and ultrastructural studies on the stomach of Schilbe mystus and the intestinal swelling of Labeo niloticus - J. Am. Sci. 7: 251-263.

Nikolsky G.V. 1963 - The ecology of fishes - Academic Press, London and New York, $352 \mathrm{p}$.

Osman A.H.K., Caceci T. 1991 - Histology of the stomach of Tilapia nilotica (Linnaeus, 1758) from the River Nile - J. Fish Biol. 38: 211-223.

Petrinec Z., Nejedli S., Kuir S., Opaëak A. 2005 Mucosubstances of the digestive tract mucosa in northern pike (Esox lucius L.) and European catfish (Silurus glanis L.) - Vet. Arhiv. 75: 317-327.

Reifel C.W., Travill A.A. 1978 - Structure and carbohydrate histochemistry of the stomach in eight species of teleosts - J. Morphol. 158: 155-168. 
Rebolledo I.M., Vial J.D. 1979 - Fine structure of the oxynticopeptic cells in the gastric glands of an elasmobranch species (Halaerurus chilensis) - Anat. Rec. 193: 805-821.

Sinha G.M., Chakrabarti P. 1986 - Scanning electron microscopic studies on the mucosa of the digestive tract in Mystus aor (Hamilton) - Proc. Indian Natn. Sci. Acad. B52: 267-273.

Smith L.S. 1989 - Digestive functions in teleost fishes - In: Fish nutrition, $2^{\text {nd }}$ ed. (Ed.) J.E. Halver, Academic Press, London: 331-421.
Sriwastwa V.M.S. 1970 - Functional anatomy of digestive organs of a fresh-water fish Rhynchobdella aculeata (Ham.) - Act. Soc. Zool. 34: 136-142.

Unal G., Cetinkaya O., Kankaya E., Elp M. 2001 - Histological study of the organogenesis of the digestive system and swim bladder of the Chalcalburnus tarichi Pallas, 1811 (Cyprinidae) - Turk. J. Zool. 25: 217-228.

Xiong D., Zhang L., Yu H., Xie C., Kong Y., Zeng Y., Huo B., Liu Z. 2011 - A study of morphological and histology of the alimentary tract of Glyptosternum maculatum (Sisoridae, silurifores) - Acta Zool. 96: 161-169. 